\title{
ITER BLANKET AND SHIELD STUDIES FOR HIGH ASPECT RATIO DESIGN OPTION*
}

Y. Gohar, H. Attaya, M. Billone, C. Johnson, J. Kopasz, S. Majumdar, R. Mattas, and D.L. Smith Argonne National Laboratory, 9700 S. Cass Ave., Argonne, IL 60439 USA

The submitted manuscript has been authored by a contractor of the U.S. Government under contract No. W-31-109ENG-38. Accordingly, the U.S. Government retains a nonexclusive, royalty-free license to publish or reproduce the published form of this contribution, or allow others to do so, for U.S. Government purposes.
D. Lousteau, B. Nelson, and D. Williamson Oak Ridge National Laboratory, P.O. Box 2009, Oak Ridge, TN 37831 USA

A. Raffray, A. Badawi, A. Ying, and M. Abdou University of California, LA, 6288 Boelter Hall, Los Angeles, CA 90024-1597 USA ANL/CP- -73462 DE92 003376

L. El-Guebaly, M. Sawan, I. Sviatoslavsky, E. Mogahed, and G. Kulcinski University of Wisconsin, 1500 Johnson Drive, Madison, WI 53706-1687 USA

The attractiveness of the high aspect ratio design (HARD) option for ITER has motivated a study to assess the blanket and shield design performance for this configuration relative to the ITER reference design. The blanket and shield have been configured to take an advantage of the HARD option. The layered solid breeder blanket concept with water-coolant and steel-structure and the water-steel shield have been used. The changes in the neutron wall loading distribution, the mechanical design, the net tritium breeding ratio, the total tritium inventory, and the nuclear heating profiles are evaluated. The tradeoff between the net tritium breeding ratio, and the fuel operating cost is analyzed. The mechanical design and the structural interaction between the first wall and the blanket is studied.

\section{Introduction}

This paper examines the impact of HARD option on the blanket and shield performance as concluded from the ITER Conceptual Design Activity (CDA). The neutron wall load distributions have been calculated for the different operating modes of HARD. The average neutron fluence has been estimated over the test ports. The net tritium bresding capability of the layered solid breeder blanket with water-coolant and steel-structure has been calculated for the HARD configuration. The required tritium breeding capability is defined as a function of the external tritium supply. Several blanket modifications have been studied to improve the blanket performance. The shield performance has been analyzed and the results compared to that of CDA.

\section{Neutron Wall Lead}

The neutron wall load distributions were calculated for the three operating modes of the High Aspect Ratio Design (HARD). The intent of the calculation is to compare the HARD capability for nuclear testing with the corresponding results from $\mathrm{CDA}$. Also, the neutron wall loading distributions are used to define the net tritium breeding capability, the nuclear responses in the toroidal field coils, and the shielding $\mathrm{p}$ trormance.

The NEWLIT code [1] was used to perform the calculations. The code uses ray tracing techniques to determine the plasma contribution to the neutron current at a given point at the first wall. The neutron source distribution is considered as a function of the magnetic flux surfaces. The function is represented as $\left[1-\left(a / a_{0}\right)^{2}\right]^{3}$. Where $a$ is the minor radius of magnetic flux surface and $a_{0}$ is the plasma minor radius. The magnetic flux surfaces were represented by the following parametric equations:

$$
\begin{aligned}
& R=R_{c}+a_{0} \cos \left(t+C_{0} \sin (t)\right), \\
& Z=K_{0} a_{0} \sin (t), \text { and } \\
& R_{c}=R_{0}+m\left(1-\left(a / a_{0}\right)^{2}\right) .
\end{aligned}
$$

The parameter $t$ varies from o to $\pi$. The plasma triangularity $\left(C_{0}\right)$, the elongation factor $\left(K_{0}\right)$, the magnetic shift $(m)$, and the other parameters are given in Table 1 . Figure 1 shows a schemaric of the first wall geometrical model, which follows closely the field lines at

* Work supported by the Office of Fusion Energy, U.S Department of Energy under Contract No.w-31-109-Eng-38. the edge of the scrapeoff layer. At the midplane, the thickness of the scrapeoff layers are 15 and $14 \mathrm{~cm}$ for the outboar 1 and inboard sections, respectively. The results of the calculations are siown in Fig. 2 for the different operating modes of the HARD where the peak reactor neutron wall loading occurs at the midplane of the outboard section. The peak values are $1.49,1.73$, and 1.95 for the inductive, steady state, and hybrid modes of operation. The variation in the peak neutron wall loading values reflect the difference in the fusion power, magnetic shift, and plasma triangularity. The average neutron wall loading values on the test section were also calculated for the three operational modes of HARD. The average values are higher than the corresponding values of CDA by 30 to $70 \%$ depending on the operating mode as shown in Table 1 .

\section{Breeding and External Requirements of Tritium}

In this study, the design guidelines and the blanket design of CDA were used to study the impact of the HARD configuration on the net tritium breeding ratio. the soiid-breeder with water-coolant and steel-structure of CDA was used for the inboard and outboard sections of HARD. Net tritium breeding estimates were made based on one-dimensional toroidal cylindrical geometry calculations. The one-dimensional results were coupled with the neutron coverage fractions of the different blanket regions. The neutron coverage fraction is corresponding to the fraction of source neutrons going directly to the region without any collisions. These coverage fractions were obtained from the neutron wall loading calculations.

The inboard blanket sectors extend vertically from $z=$ $-2.69 \mathrm{~m}$ to $\mathrm{z}=2.69 \mathrm{~m}$. The outboard blanket sectors extend from $\mathrm{z}=-3.85 \mathrm{~m}$ to $\mathrm{z}=2.86 \mathrm{~m}$ with sixteen midplane ports occupied by other components. The port dimensions are $1.27 \mathrm{~m}$ and $2.3 \mathrm{~m}$ in the toroidal and poloidal directions, respectively. The neutron fraction lost to the sixteen ports is about $10 \%$. It is about the same value as of CDA although the total port surface area is $24 \%$ less than CDA. Also, the neutron wall loading peaking at the ports is higher in HARD. These two factors are balancing each nther, which leads to the same neutron coverage for the ports. The neutron coverage of the outboard blanket is reduced by $9 \%$ relative to CDA. Also, the divertor zone receives $21 \%$ of the neutrons which represents $34 \%$ increase from CDA. These two changes have a negative impact on the net tritium breeding ratio. The neutron coverage of the inboard blanket is increased from $16 \%$ in CDA to $20 \%$ in HARD. The net impact on the tritium breeding ratio is about $8 \%$ less tritium breeding as shown in Table 2 .

The different blanket design options of CDA were reevaluated for HARD with respect to the net tritium breeding ratio. The blankets geometrical parameters of CDA $[2,3]$ were used to study the impact of the HARD geometrical configuration. The radial build for the solid breeder blanket varies poloidally according to the neutron wall loading variation in order to maintain constant minimum breeder temperature in the poloidal direction. The effect of the $0.5 \mathrm{~cm}$ thick copper stabilizer loops in the outboard blanket has been evaluated. The blanket has a single $\mathrm{Li}_{2} \mathrm{O}$ layer in the inboard blanket and two or three in the outboard blanket. The lithium in the $\mathrm{Li}_{2} \mathrm{O}$ is enriched to $95 \%$. The tritium breeding results have been modified to account for the actual neutron coverage, the assembly gaps, and the side walls. The net tritium breeding ratios are 0.78 and 0.87 for the design with two and three breeding

OISTRIBUTION OF THIS DOCUMENT IS UNLIMITES 


\section{DISCLAIMER}

This report was prepared as an account of work sponsored by an agency of the United States Government. Neither the United States Government nor any agency thereof, nor any of their employees, makes any warranty, express or implied, or assumes any legal liability or responsibility for the accuracy, completeness, or usefulness of any information, apparatus, product, or process disclosed, or represents that its use would not infringe privately owned rights. Reference herein to any specific commercial product, process, or service by trade name, tradeniark, manufacturer, or otherwise does not necessarily constitute or in:piy its endorsement, recommendation, or favoring by the United States Government or any agency thereof. The views and opinions of authors expressed herein do not necessarily state or reflect those of the United States Government or any agency thereof. 
Table 1

Comparison of Neutron Source Parameters and Neutron Wall Loading Results for HARD and CDA

\begin{tabular}{|c|c|c|c|c|c|}
\hline \multirow[b]{2}{*}{ Parameter } & \multicolumn{2}{|c|}{ HARD } & \multirow[b]{2}{*}{ Hybrid } & $\begin{array}{c}\text { CDA } \\
\text { Physics }\end{array}$ & \multirow[b]{2}{*}{ Technology } \\
\hline & Inductive & Steady State & & Physics & \\
\hline Major Radius (m) & 6.33 & 6.33 & 6.33 & 6.00 & 6.00 \\
\hline Minor Radius (m) & 1.58 & 1.58 & 1.58 & 2.15 & 2.15 \\
\hline Elongation & 2.00 & 2.00 & 2.00 & 1.982 & 1.982 \\
\hline Triangularity & 0.289 & 0.285 & 0.284 & 0.383 & 0.383 \\
\hline Magnetic Shift (m) & 0.144 & 0.266 & 0.284 & 0.255 & 0.255 \\
\hline Fusion Power (MW) & 850 & 960 & 1080 & 1100 & 860 \\
\hline First Wall Area $\left(\mathrm{m}^{2}\right)$ & 833 & 833 & 833 & 944 & 944 \\
\hline \multicolumn{6}{|l|}{ Wall Loading (MW/m $\left./ \mathrm{m}^{2}\right)$} \\
\hline First Wall Average & 0.817 & 0.923 & 1.038 & 0.934 & 0.73 \\
\hline Maximum Value & 1.490 & 1.728 & 1.952 & 1.540 & 1.204 \\
\hline Max. Inboard Value & 1.149 & 1.245 & 1.392 & 1.131 & 0.844 \\
\hline Test Section Average & 1.396 & 1.616 & 1.825 & 1.374 & 1.074 \\
\hline
\end{tabular}

Table 2

Comparison of Neutron Coverage and Net Tritium Breeding Parameters for HARD and CDA

\begin{tabular}{lcc}
\hline Parameters & CDA & HARD \\
\hline Inboard Blanket Extent, m & -3.40 to 3.40 & -2.69 to 2.69 \\
Neutron Coverage of Inboard Blanket, \% & 16.4 & 19.6 \\
Outboard Blanket Extent, m & -4.80 to 4.80 & -3.85 to 2.86 \\
Neutron Coverage of Outboard Blanket, \% & 69.1 & 59.6 \\
Divertor Neutron Coverage, \% & 15.5 & 20.8 \\
Port Neutron Coverage, \% & 10.3 & 9.9 \\
Net Tritium Breeding Ratios of Different Options & & \\
Two breeder zones and copper stabilizer & 0.84 & 0.78 \\
Two breeder zones without copper stabilizer & 0.87 & 0.80 \\
Three breeder zones and copper stabilizer & 0.92 & 0.85 \\
Three breeder zones without copper stabilizer & 0.95 & 0.87
\end{tabular}

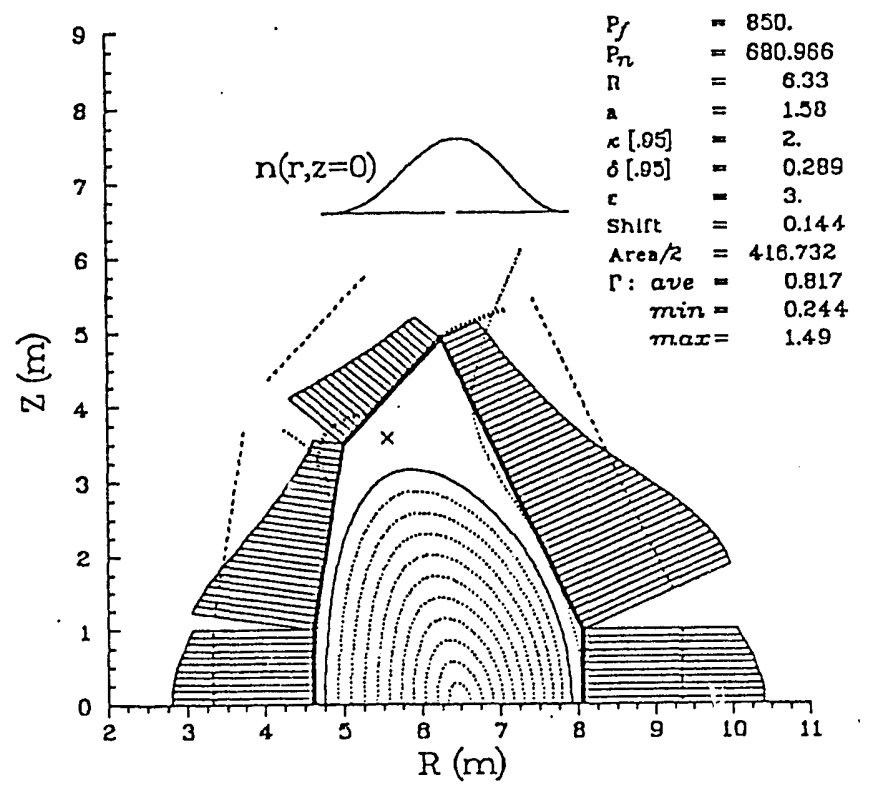

Figure 1

HARD first wall model and neutron wall loading for the ignited mode.

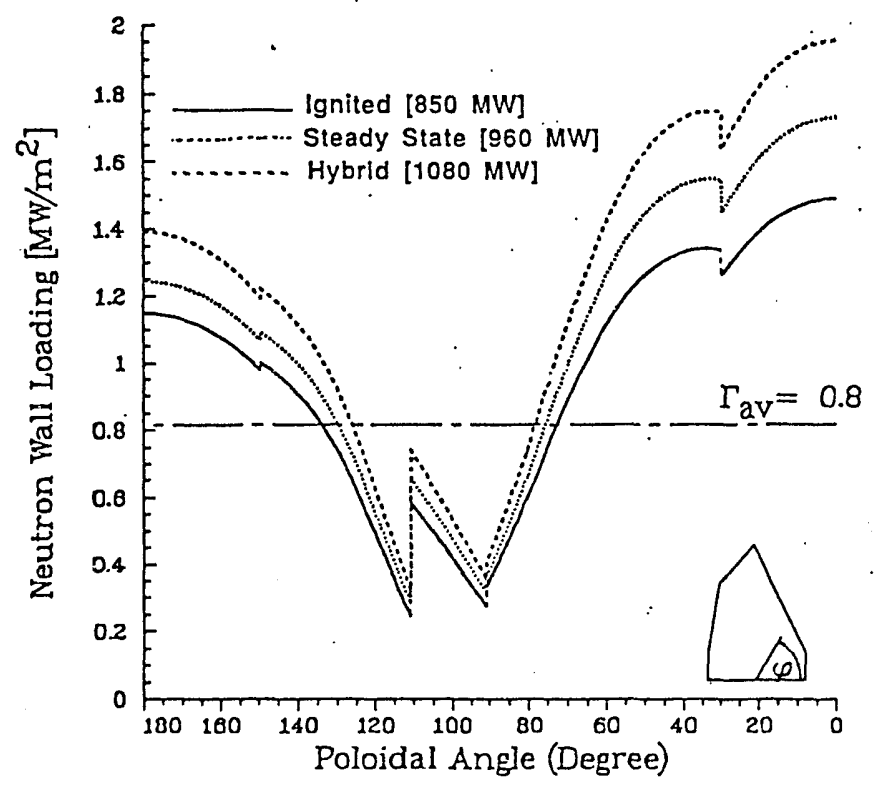

Figure 2

HARD neutral wall loading for the three modes of operation. 
layers. The copper stabilizer loops in the outboard blanket reduce the net tritium breeding ratio by $3 \%$ as shown in Table 2 . In inboard section, the effect of the loops is less than $1 \%$ on the net tritium breeding ratio because of low contribution of the inboard blanket.

The tritium requirements were evaluated for the HARD option as a function of the extemal tritium supply rates. It is assumed that the external tritium inventory available for ITER at start of operation is $20 \mathrm{Kg}$ and the steady state inventory in the ITER components is $5 \mathrm{Kg}$. The calculations were normalized to the same average neutron fluence of $3 \mathrm{MW} \cdot \mathrm{a} / \mathrm{m}^{2}$ at the midplane test sections. Table 3 gives the minimum tritium breeding ratios calculated for both options of ITER. The HARD option requires less net tritium breeding ratio for the same external tritium supply rate because of the higher average neutron wall loading at the test section compared to the CDA option. This can be translated to less external tritium supply, less operating time or relaxing the required tritium breeding ratio from the blanket to achieve the same fluence in the test sections.

\section{Blanket Design Changes for HARD}

Several blanket design changes have been considered to benefit from the HARD configuration and improve the performance. The first change is to divide the blanket sector to six modules in the poloidal direction. These blanket modules are attached to the continuous shield sector where the water manifolds are located. With this change, the replacement procedure for the first wall, blanket, and shield is the same as of CDA where the sector is replaced as a single unit. This design change does simplify the fabrication and assembly procedures of the blanket. Also, it increases the stiffness of the first wall structure to accommodate the plasma disruption loads.

The midplane module of the outboard blanket has been analyzed for thermal and helium pressure $(0.1 \mathrm{MPa})$ loadings. The module extends about $1 \mathrm{~m}$ in the toroidal and poloidal directions. The poloidal and toroidal curvarures of the first wall were included in the model. Both the first wall and the blanket coolant panel were assumed to consist of three layers, a layer containing the water channels enclosed between two steel layers. The cross-section of the side walls between the first wall and the coolant panel were the same as that of the first wall. The first wall and the coolant panel were added to form the side wall between the coolant panel and the shield. The steel dimensions were taken as the CDA design. The heat flux on the front plate of the first wall as taken as $0.3 \mathrm{MW} / \mathrm{m}^{2}$ while the heat flux on the back plate of the first wall from the blanket was treated as a variable. The radial variation of the temperature distributions was adjusted to the match the heat flux values. The results show the existence of an optimum heat load value from the blanket, which minimizes the thermal stresses as shown in Fig. 3. At the optimum heat load value, the first wall displacement is very small. The results show the maximum stress values occur at the corners of the module that can be reduced by adjusting the geometry at these points.

Another study was: performed to improve the tritium breeding capability of the blanket and to study the use of high density beryllium. The CDA design guidelines with respect to the temperature limits for each blanket material were used for this study. The obtained local tritium breeding ratio is $9 \%$ higher than the corresponding value of $\mathrm{CDA}$.

\section{Shielding Performance}

Shielding analysis has been performed for the proposed HARD design using one-dimensional model and the shielding performance for this configuration is compared to that for the CDA design [4]. The one-dimensional discrete ordinates code ONEDANT and a 66-coupled group nuclear cata library based on ENDF/B-V were used to carry out the transport calculations. Three different operating modes, namely, the inductive, steady state, and hybrid modes are proposed for HARD. The fusion power and consequently, the neutron wall loadings vary depending on the mode of operation. The shielding analysis has been performed for the hybrid case which represents the worst case from the shielding standpoint since it yields the highest neutron wall loading. The peak inboard wall loading in the hybrid case with $1080 \mathrm{MW}$ fusion power is $1.39 \mathrm{MW} / \mathrm{m}^{2}$. Magnet nuclear heating results can be determined for the other modes of operation by scaling with the fusion power ( 850 and $960 \mathrm{MW}$ for the ignited and steady state modes, respectively). On the other hand the end-of-life fluence and insulator dose should be independent of fusion power as long as the ITER fluence goal of $3 \mathrm{MW} \cdot \mathrm{y} / \mathrm{m}^{2}$ is maintained.

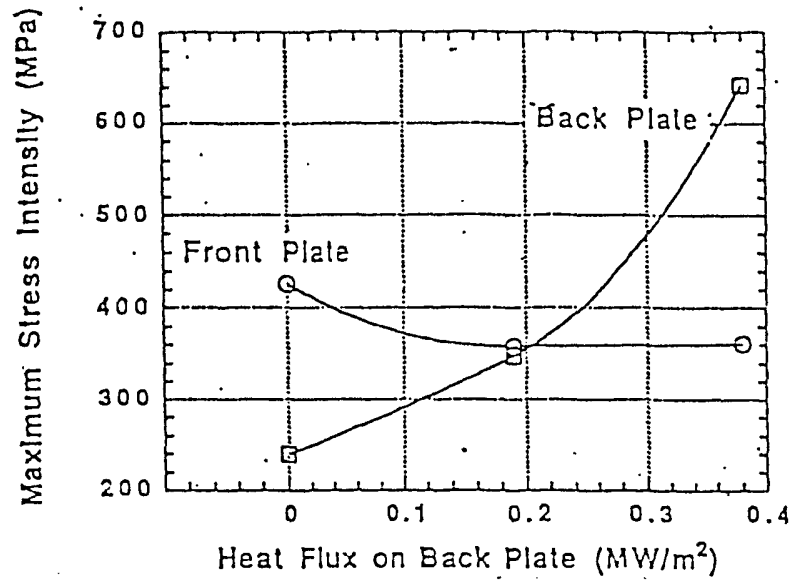

Figure 3

Variations of the maximum stress intensity in the front and back plates of the first wall as a function of the heat flux on the back plate for a $4 \times 4 \times 5 \mathrm{~mm}$ first wall design.

The design parameters pertinent to shielding analysis are given in Table 4 for the HARD (hybrid) and CDA (physics phase) designs. The parameters are given for the three regions with critical shielding space. These are the inboard region, the divertor region and the shield recess area located between the end of the inboard blanket and the inner end of the divertor plate. For comparable fusion power, the peak neutron wall loading values in these regions are higher than those in the CDA design because of the higher aspect ratio on the HARD design. The assembly gap between the back of the shield and the vacuum vessel (V.V.) is $4 \mathrm{~cm}$ in HARD compared to $2 \mathrm{~cm}$ in $\mathrm{CDA}$. Furthermore, the inboard (i/b) blanket/shield/gap/V.V. thickness at the midplane is $83 \mathrm{~cm}$ vs. $84 \mathrm{~cm}$ in CDA. This means that $3 \mathrm{~cm}$ of the shield is replaced by void. $3 \mathrm{~cm}$ less shield translates into $\sim 50 \%$ higher damage at the magnet. Hence, the peak end-of-life insulator dose at the inner legs of the TF coils will exceed the design limit for epoxy. The insulator dose in the divertor region of HARD is acceptable as as result of using a thicker coil case.

The nuclear heating in the TF magnets for the three critical regions $(\mathrm{i} / \mathrm{b}$, recess, and divertor) was calculated taking into account the poloidal variation of neutron wall loading and blanket/shield/V.V. thickness. The results are summarized in Table 5 for the HARD and CDA designs. Radiation streaming through the different penetrations is assumed :o contribute $4 \mathrm{~kW}$ to the total magnet nuclear heating. Most of the heating in the inboard region is generated in the $3 \mathrm{~m}$ high middle section. Heating in this region is doubled due to the larger magnet volume ( $70 \%$ more), higher wall loading, and thinner shield, compared to the CDA design. The results indicate that the total heating loads are 68,53 , and $60 \mathrm{~kW}$ in the hybrid, ignited, and steady state modes of operation, respectively.

In order to reduce the heating to a reasonable level and meet the insulator does limit for $3 \mathrm{MW} \cdot \mathrm{y} / \mathrm{m}^{2}$ fluence, several modifications to the present HARD design need to be adopted. The total i/b blanket/shield/gap/V.V. thickness at midplane should be restored to $84 \mathrm{~cm}$ with the gap reduced to $2 \mathrm{~cm}$ as in the CDA design. In addition, it is necessary to extend the upper parts of the side modules of the outboard blanket inward up to the plasma 
Table 3. Minimum Tritium Breeding Ratio Required for Different Tritium Supply Rates Normalized to $3 \mathrm{MWa} / \mathrm{m}^{2}$ Fluence at the Test Section

\begin{tabular}{|c|c|c|c|c|}
\hline $\begin{array}{c}\text { Tritium } \\
\text { Supply Rate } \\
\mathbf{K} \mathbf{g} / \mathbf{y}\end{array}$ & $\begin{array}{c}\text { Total Tritium } \\
\text { Purchased, } \\
\text { Kg }\end{array}$ & $\begin{array}{c}\text { Cost of } \\
\text { Purchastd } \\
\text { Tritium B\$ }\end{array}$ & $\begin{array}{c}\text { Required } \\
\text { Tritium Breeding } \\
\text { HARD }\end{array}$ & $\begin{array}{l}\text { Ratio } \\
\text { CDA }\end{array}$ \\
\hline $\begin{array}{l}1 \\
2 \\
3 \\
4\end{array}$ & $\begin{array}{l}30 \\
40 \\
50 \\
60\end{array}$ & $\begin{array}{l}0.87 \\
1.16 \\
1.45 \\
1.74\end{array}$ & $\begin{array}{l}0.82 \\
0.72 \\
0.62 \\
0.52\end{array}$ & $\begin{array}{l}0.86 \\
0.79 \\
0.71 \\
0.64\end{array}$ \\
\hline
\end{tabular}

Table 4. Reievant Shielding Design Parameters

\begin{tabular}{|c|c|c|}
\hline & $\begin{array}{l}\text { CDA } \\
\text { (Physics Phase) }\end{array}$ & $\begin{array}{l}\text { HARD } \\
\text { (Hybrid) }\end{array}$ \\
\hline Fusion Power (MW) & 1100 & 1080 \\
\hline $\begin{array}{l}\text { Average Wall Loading }\left(\mathrm{MW} / \mathrm{m}^{2}\right) \\
\text { Inboard Region }\end{array}$ & 0.93 & 1.04 \\
\hline $\begin{array}{l}\text { Peak Wall Loading }\left(\mathrm{MW} / \mathrm{m}^{2} \text { ) }\right. \\
\text { Blanket/Shield/Gap/V.V. thickness* (cm) } \\
\text { Gap Thickness }(\mathrm{cm})\end{array}$ & $\begin{array}{l}1.13 \\
84 \\
2\end{array}$ & $\begin{array}{c}1.39 \\
83 \\
4\end{array}$ \\
\hline 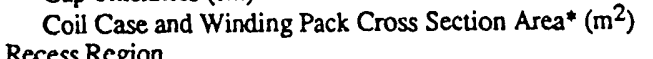 & 6.3 & 10.8 \\
\hline $\begin{array}{l}\text { Recess Region } \\
\text { Peak Wall loading }\left(\mathrm{MW} / \mathrm{m}^{2}\right) \\
\text { Blanke/Shield/Gap/V.V. Thickness }(\mathrm{cm})\end{array}$ & $\begin{array}{c}0.22 \\
70\end{array}$ & $\begin{array}{l}0.25 \\
70.6\end{array}$ \\
\hline $\begin{array}{l}\text { Divertor Region } \\
\text { Peak Wall Loadingt (MW//nw) } \\
\text { BlankeU/Shield/Gap/V.V. Thicknesst (cm) } \\
\text { Coil Case Thickness }(\mathrm{cm})\end{array}$ & $\begin{array}{l}0.67 \\
58 \\
26\end{array}$ & $\begin{array}{l}0.75 \\
56 \\
39\end{array}$ \\
\hline
\end{tabular}

* At midplane. $\quad+$ At i/b side of outer end of divertor plate.

Table 5. Total Nuclear Heating in TF Coils

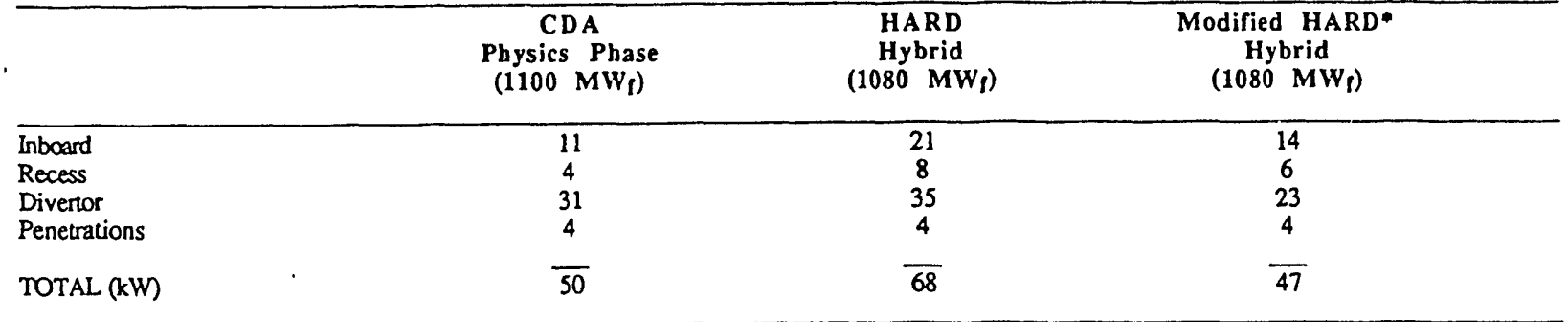

* With $2 \mathrm{~cm}$ gap, $84 \mathrm{~cm}$ i/b blanke//shield/gap/V.V. and modified o/b blanket side modules.

boundary (similar to the lower parts) in order to provide extra shielding for the upper divertor region. Notice that the side modules are located underneath magnets and there will be no interference with maintenance. The impact of this modification is to reduce the divertor heating by $\sim 5 \mathrm{~kW}$. If these changes take place, the heating in the magnets will be $47 \mathrm{~kW}$ for the hybrid case, as detailed in the last column of Table 2.

\section{Conclusions}

This paper examines the impact of HARD option on the blanket and shield performance as concluded from CDA. The neutron wall load distributions have been calculated for the different operating modes of HARD. The average neutron wall load over the test ports is 30 to $70 \%$ higher than CDA which increases the testing capability of ITER. The net tritium breeding capability of HARD has been calculated based on the use of CDA blanket design. The net tritium breeding ratio is $8 \%$ less than CDA. However the increased average neutron wall load over the test sections overrides the impact on the external tritium supply because of shorter operating time for the same neutron fluence. The shielding analysis of HARD has suggested several modifications to meet the design limits of CDA. The total inboard thickness at midplane should be restored to $84 \mathrm{~cm}$ with the vacuum gap between the shield and the vacuum vessel reduced to $2 \mathrm{~cm}$ as in CDA, or $86 \mathrm{~cm}$ inboard thickness with the current gap thickness of $4 \mathrm{~cm}$. In addition, it is necessary to extend the upper parts of the side modules to provide extra shielding for the upper divertor region.

\section{References}

[1] H. Attaya and M. Sawan, "NEWLIT - A General Code for Neutron Wall Loading Distribution in Toroidal Reactors," Fusion Technology, 8/1,608 (1985).

[2] Y. Gohar, H. Attaya, M. Billone et al., "U.S. Solid Breeder Blanket Design for ITER," Fusion Technology, Vol. 19, No. 3 (1991).

[3] Y. Gohar, H. Attaya, M. Billone et al., "U.S. Technical Report for the ITER/Shield - A. Blanket," ITER-TN-BL-5-0-3 (November 1990).

[4] L.A. El-Guebaly, "Overview of the U.S.-ITER Magnet Shield: Concept and Problem"," Fusion Technology, Vol. 19, No. 3 (1991) 

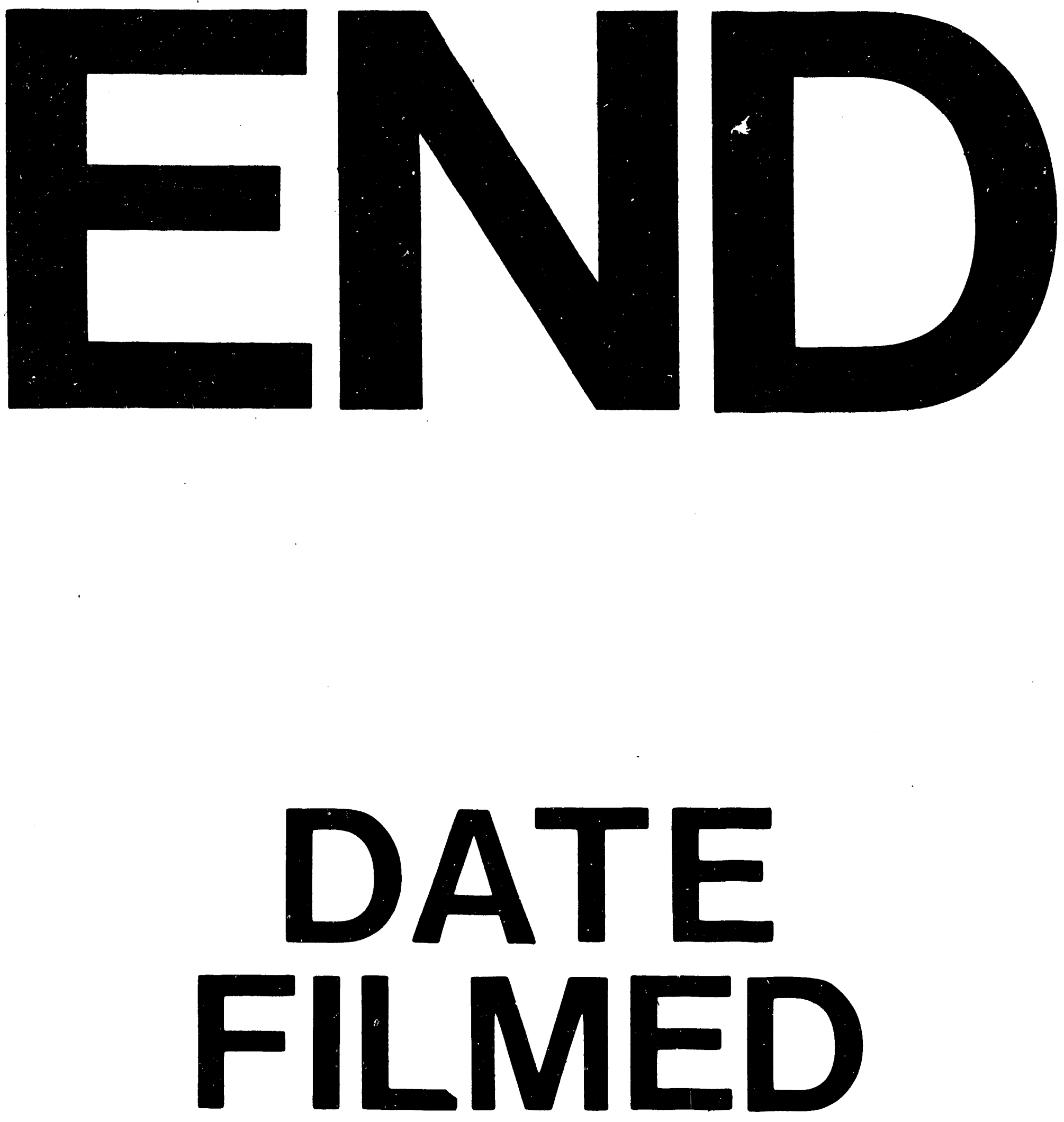

1

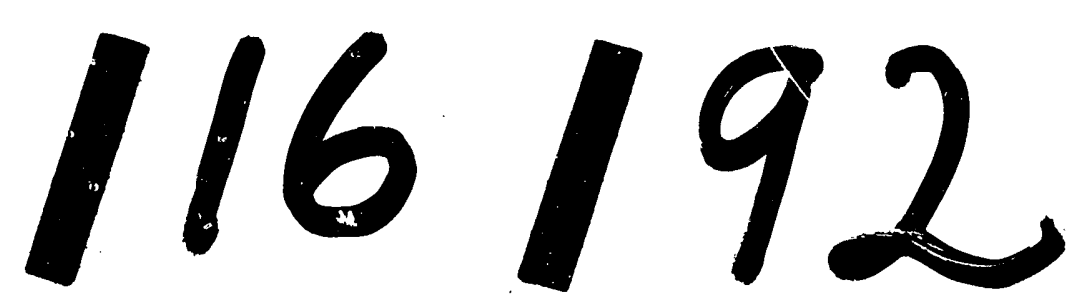


